Proceedings

\title{
Sustainable Building: High Performance Timber Bridges ${ }^{\dagger}$
}

\author{
Julio Vivas * and Juan Carlos Santos \\ Media Madera Ingenieros, 33430 Asturias, Spain; info@mediamadera.com \\ * Correspondence: juliovivas@mediamadera.com; Tel.: +34-985-516-916 \\ + Presented at the 2nd International Research Conference on Sustainable Energy, Engineering, Materials and \\ Environment (IRCSEEME), Mieres, Spain, 25-27 July 2018.
}

Published: 15 January 2019

\begin{abstract}
Steel and concrete are fantastic materials that will continue to be fundamental in the future, but we cannot ignore their high energy costs and carbon footprint. As well as is expected a transition from fossils fuels to renewable energy sources, the change from fossil fuel-based building materials to renewables will also be inevitable in the future of construction.
\end{abstract}

Keywords: timber footbridges; carbon footprint; planning

\section{Introduction}

As far as climate change is the greatest environmental global threat, sustainable construction is the way forward for the building industry to play its part towards achieving a sustainable and healthier world.

Timber is a natural renewable material which is directly available in nature, requires much less energy than other building materials and, in addition, stores $\mathrm{CO}_{2}$; it is estimated that an increase of $10 \%$ in the percentage of timber used in construction in Europe would make it possible to save $25 \%$ of the total reductions foreseen in the Kyoto Protocol

The use of timber as a structural material is not new, in fact wood has been used in construction for thousands of years. However, at the present time, steel and concrete have almost entirely replaced it as a building material: often nowadays, wood is considered to be a low strength material with very poor durability associated with complicated and costly maintenance works.

Therefore, when a few years ago, due to the width extension of the A8 motorway, an old conventional metallic footbridge had to be replaced, the "timber option" had to overcome a large number of obstacles before becoming a reality.

\section{Why Use Timber for Today's Bridges?}

It's necessary to deal with some deeply rooted wrong preconceived ideas, such as:

\subsection{Durability}

Actually wood, as an organic material, is destined to reincorporate to the environment, constituting the base of feeding of living organism, especially fungi and insects. However, when timber construction kept in suitable conditions, mainly dry and ventilated, it is one of the materials of greater durability.

The prejudice that it has a short life is disproved by the many historical timber structures that survive, from Japanese temples to Norwegian stave churches. Decay of timber will generally occur where the moisture content is above $22 \%$ for a prolonged period of time, it is the design of the structure itself which plays the most important part. To ensure that the timber is not susceptible to 
high moisture contents in service, additionally, chemical preservative treatments may be applied as a second line ensuring a good durability even for the worst conditions.

\subsection{Resistance}

The strength of timber comes from the natural properties of the wood and the way the tree grows. Timber is, in fact, a material with a high degree of specialization ad complexity. It can be considered as a bundle of tubes oriented in the longitudinal direction with two main components: Lignin which has a higher compressive strength than that of concrete, and cellulose, that has a tensile strength higher than that of steel. The combination of these two materials gives wood a surprising very high strength-to-weight ratio. It can offer lightweight structural solutions resulting in benefits such as reduced foundation loads and ease of lifting prefabricated elements during transport and assembly. In fact, new composite materials (such as carbon fiber) copy this strategy by combining materials of different properties that complement each other.

\subsection{Sustainability}

The use of timber in construction, is often associated with deforestation but the truth is radically different: where certification and sustainable forest management is in place, the use of timber is leading to a significant increase in the forest area.

In addition, as a natural and renewable building material timber has excellent ecological attributes. It acts as a carbon sink and has low embodied energy. The energy needed to convert trees into wood and hence into structural timber is significantly lower than that required by other structural materials.

\section{Designing a Timber Bridge}

So, with these were convincing arguments we were able to persuade the authorities to consider the construction of a wooden bridge. The next step is the development of a convincing design proposal.

The motorway has a width of $60 \mathrm{~m}$, and it must also be necessary to leave a clearance of at least $5.5 \mathrm{~m}$ above the road (Figure 1). Besides, this motorway support a very heavy traffic. The need to interrupt traffic during bridge placement limited access to the site to just a few hours at night. Hence, design has to give priority to make the assembly as quickly as possible. To achieve this, the bridge had to be completely prefabricated in elements off site, which could be transported and assembled in the easiest and fastest possible way.

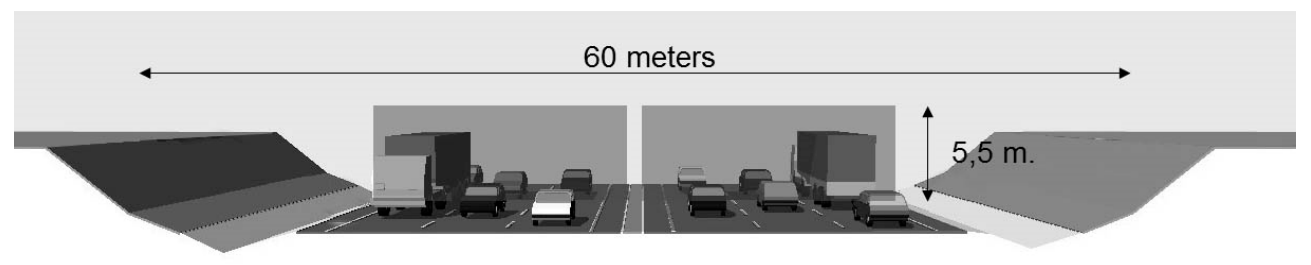

Figure 1. Width and clearance of the motorway.

Design begins with the placement of a completely straight deck, but bending the board, we could reduce the distance above the floor and maintain, at the same time, the clearance above the road. The final curvature of the deck was restricted by the accessibility regulations for the flor slope (Figure 2).

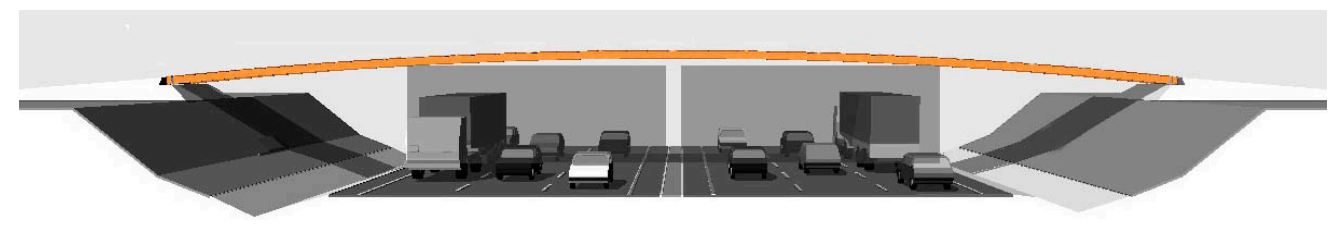

Figure 2. Curve deck. 
Placing a roof in the bridge allows protect pedestrians from the rainy weather and is the best way to keep dry the structure and ensure long life service. So, with the placement of uprights between the roof and the deck the main truss of the bridge is configured (Figure 3).

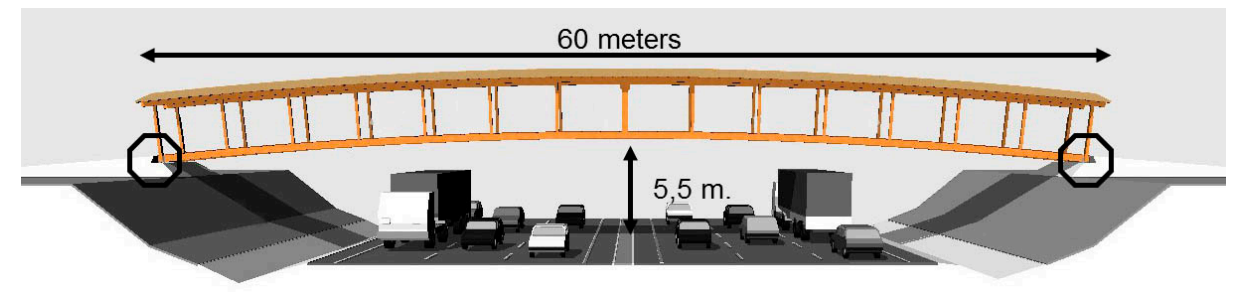

Figure 3. The main truss.

The challenge was ensuring an optimum structural system with an effectively response to the loads required by standards and which can be transported and assembled in the easiest and fastest possible way. So, the incorporation of a double arch reinforces the main truss: the deck is hanged from the arches by the uprights, which work as tension, but work as columns at the sides of the bridge.

A numerical model, representative of the system (Figure 4), allowed us to check the effectiveness of the proposed structure: Stress caused by vertical loads are evenly distributed, with a predominance of axial forces, which are the "good ones" for a material such as timber, with high resistance in the direction parallel to the grain but low capacity in perpendicular. In addition, this system allows to set points with zero bending moment, where can be designed simple connections that can be easily assembled on site (Figure 5).

So, taking advantage of these points of zero bending, we can divide the bridge into four modules which can be prefabricated, and their measures was adjusted to allow the transportation by road.

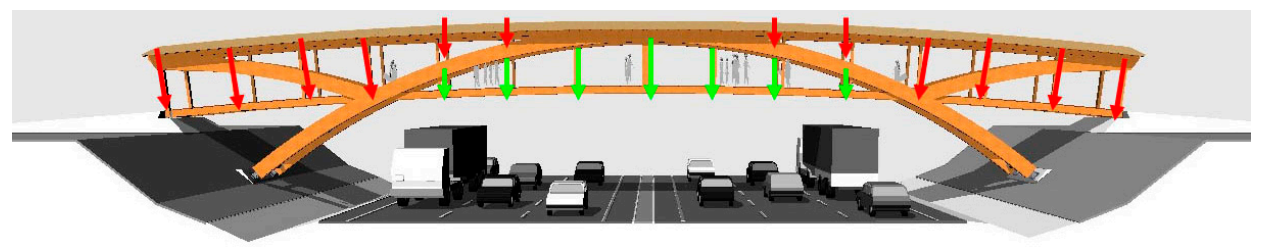

Figure 4. Final structural system.

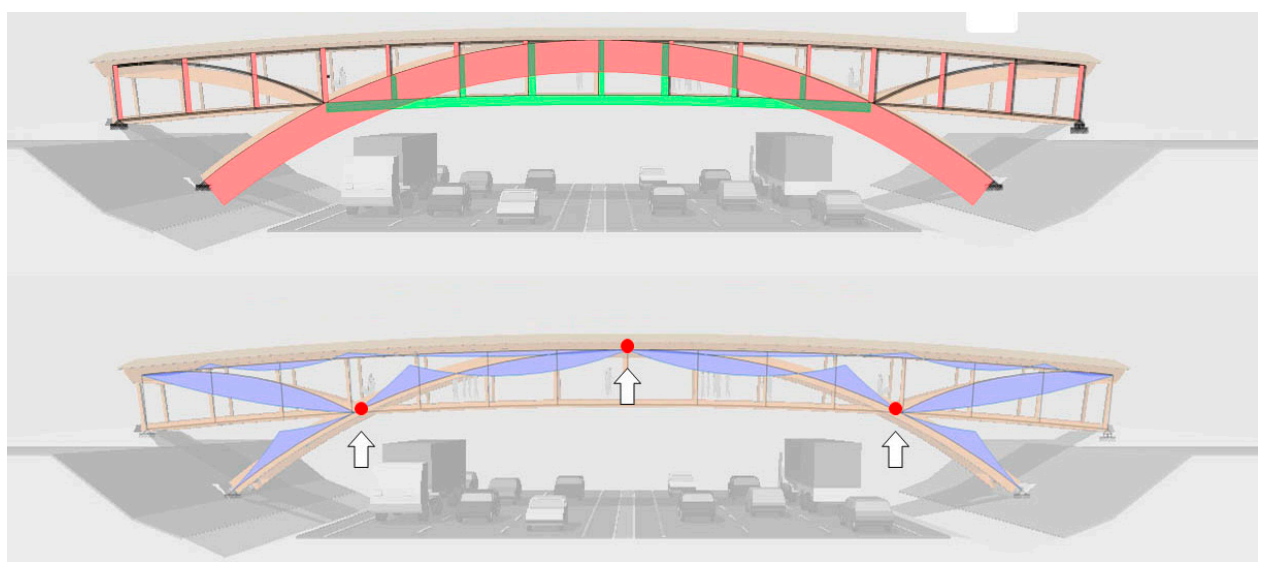

Figure 5. Axial and bending stress diagrams.

\section{Building and Placing the Bridge}

Each module of the bridge was completely prefabricated in the factory, over three hundred kilometers from the final location. There, once the fabrication was completed, each element was loaded onto large trucks and transported directly to the worksite, where two cranes were waiting to lift each module. 
A temporary structure placed in the middle of the motorway was also used. In this way, both principal modules could be placed independently so they could be afterwards connected. The assembly ended with the placement of the modules below arches assuring their support on the main foundations, in that moment the central support could be removed and the cranes departed (Figure 6).
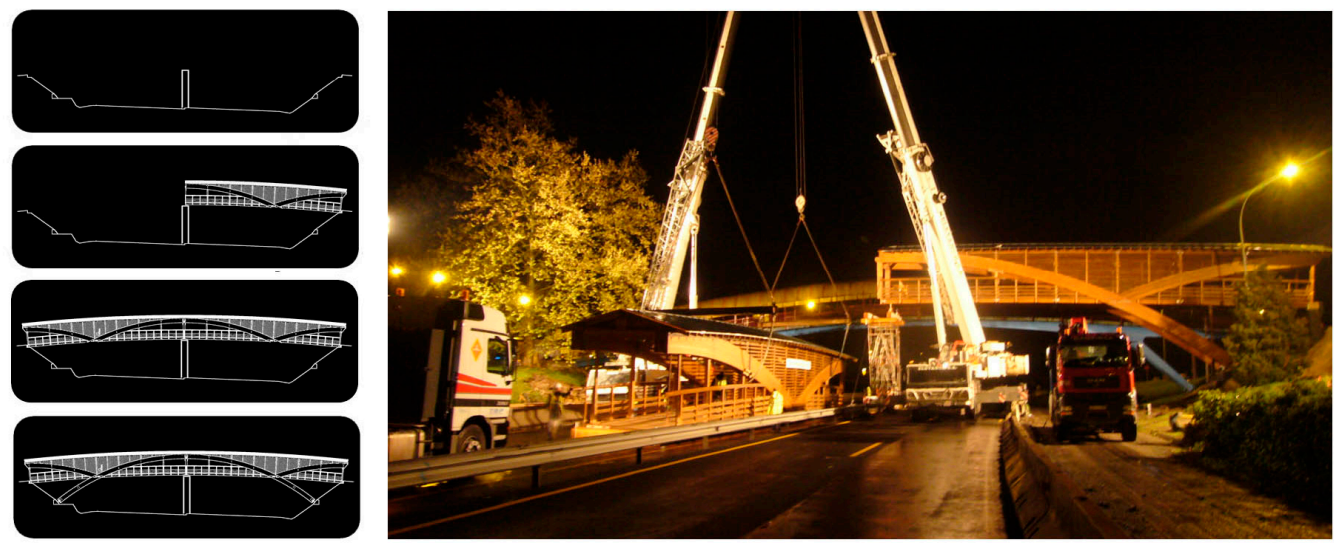

Figure 6. Assembly sequence of the footbridge.

\section{Discussion and Conclusions}

Steel and concrete are fantastic materials that will remain fundamental in the future, but we can not ignore their high energy cost and high carbon footprint. Just as a shift from fossil fuels to renewable energy sources is foreseeable, the shift from fossil fuel based building materials to renewables will also be inevitable in the future of construction.

Large timber bridges will surely be an important part of the next generation of sustainable high technology development constructions. Timber structures "sequester" carbon dioxide and offer solutions of low energy cost (Figure 7).

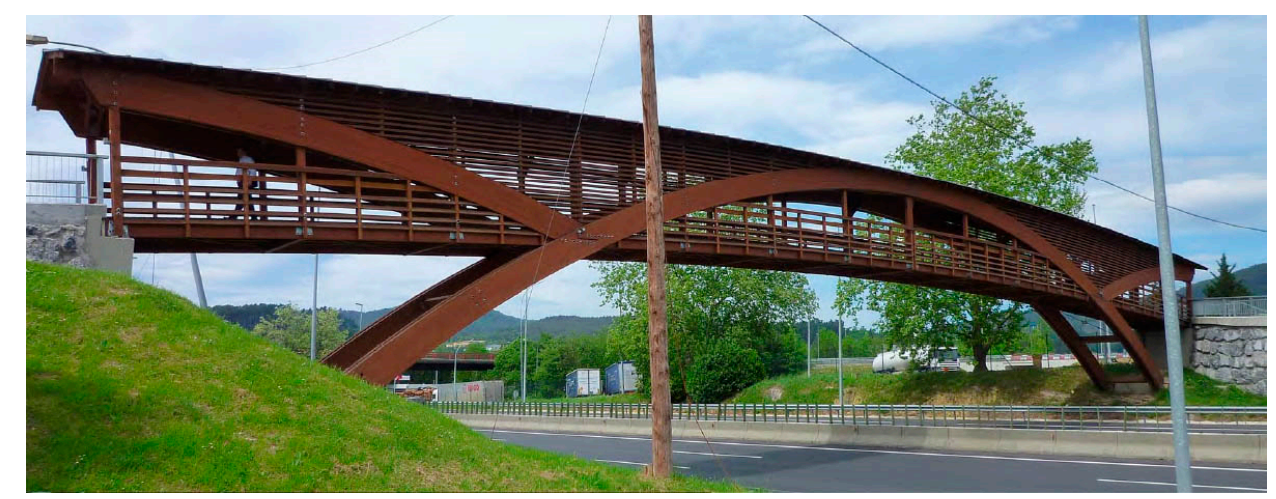

Figure 7. Finished bridge.

(C) 2019 by the authors. Licensee MDPI, Basel, Switzerland. This article is an open access article distributed under the terms and conditions of the Creative Commons Attribution (CC BY) license (http://creativecommons.org/licenses/by/4.0/). 